\title{
Aspiration of a fractured tracheostomy cannula in a pediatric patient
}

\author{
Molly Kraus, MD® $•$ Michelle LeRiger, MD
}

Received: 11 August 2016/Revised: 23 August 2016/Accepted: 31 August 2016/Published online: 12 October 2016

(C) Canadian Anesthesiologists' Society 2016

A seven-year-old, 22-kg male with CHARGE syndrome (i.e., coloboma of the eye; heart disease; atresia of the choanae; retarded growth, development, and/or central nervous system anomalies; genital hypoplasia in males; ear anomalies and/or deafness) ${ }^{1}$ and tracheostomy dependence presented to the emergency department after a vigorous coughing spell. Upon attempted suctioning, his mother noted that the tracheostomy shaft had become disconnected from the neck plate. He exhibited mildly laboured breathing, had clear secretions from the stoma, and maintained oxygen saturations of $93-98 \%$ on room air. A chest radiograph (Figure A) confirmed a foreign body in the trachea extending into the right mainstem bronchus. His last gastrostomy tube feeding had been five hours prior.

He was brought to the operating room for micro-direct laryngoscopy and bronchoscopy (MLB) to retrieve the foreign body. Upon inhalational induction, brown gastric fluid flowed from the tracheostomy site and his mouth. He was turned to his right side, both sites were suctioned, and a 3.5-cuffed endotracheal tube (ETT) was advanced through the stoma. The ETT was aspirated but with minimal return. An orogastric tube was passed to decompress the stomach. During MLB, the tracheostomy shaft was found to be resting in the distal trachea (Figure B). Using a rigid ventilating bronchoscope and forceps, the surgeon removed the tube (Figure C) through the glottis and out the mouth. At the conclusion of the procedure, a 3.5 uncuffed pediatric Bivona ${ }^{\mathrm{TM}}$ (Bivona Medical Technologies, Gary, IN, USA), was advanced easily through the stoma.

Fortunately, fractures of tracheostomy tubes are rare. Patients may initially be misdiagnosed with asthma, chronic bronchitis, or pneumonia until a chest radiograph is obtained. Piromchai et al. reviewed 20 such case reports, seven of which involved children. The fractured tube was most commonly aspirated into the trachea or right main bronchus, and the break usually occurred between the tube

M. Kraus, MD $(\bowtie) \cdot$ M. LeRiger, MD

Division of Pediatric Anesthesiology, Children's Hospital and Medical Center, University of Nebraska Medical Center, Omaha, NE, USA

e-mail: mokraus@childrensomaha.org 


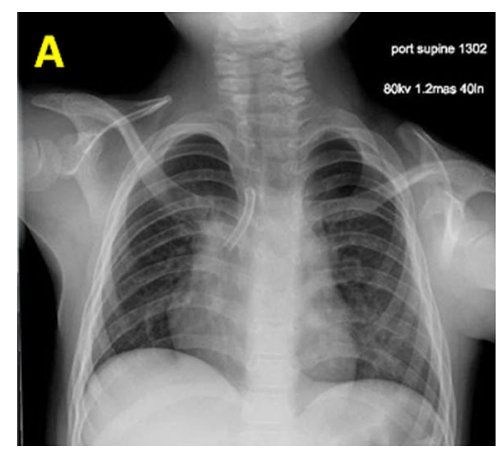

Figure Chest radiograph (A) of a tracheostomy cannula in the trachea extending into the right mainstem bronchus. The fractured tracheostomy cannula (B) is seen through a rigid bronchoscope that

and the neck plate in both polyvinyl chloride and metallic tracheostomy tubes. ${ }^{2}$

Conflicts of interest None declared.

Editorial responsibility This submission was handled by Dr. Hilary P. Grocott, Editor-in-Chief, Canadian Journal of Anesthesia.
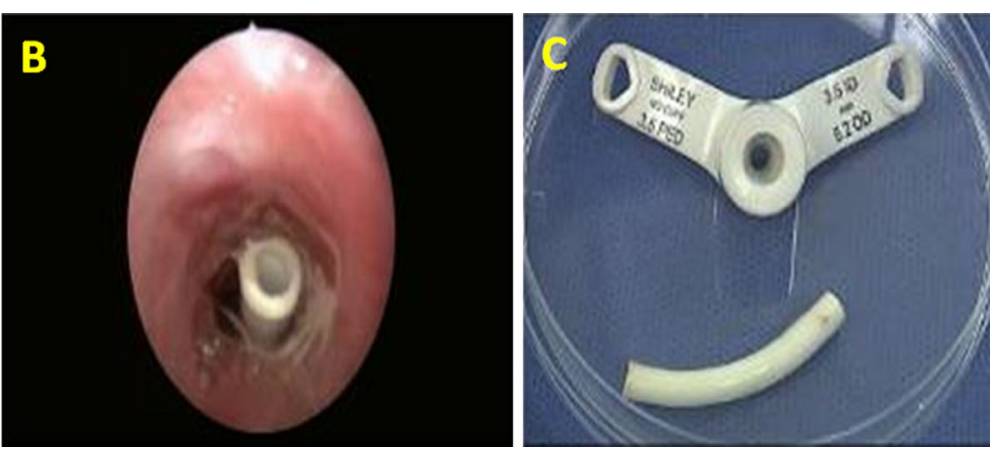

was advanced into the trachea. The inner cannula (C) was inspected after its retrieval, which revealed a fracture at the neck plate site.

\section{References}

1. Davenport SL, Hefner MA, Mitchell JA. The spectrum of clinical features in CHARGE syndrome. Clinical Genetics 1986; 29: 298-310.

2. Piromchai $P$, Lertchanaruengrit $P$, Vatanasapt $P$, Ratanaanekchai $T$, Thanaviratananich $S$. Fractured metallic tracheostomy tube in a child: a case report and review of the literature. J Med Case Rep 2010; 4: 234. 